\title{
Nursing research in heart failure care: a position statement of the american association of heart failure nurses (AAHFN)
}

Kelly D. Stamp, Marilyn Prasun, Christopher S. Lee, Tiny J aarsma, Mariann R. Piano and Nancy M. Albert

The self-archived postprint version of this journal article is available at Linköping University Institutional Repository (DiVA):

http:/ / urn.kb.se/ resolve?urn=urn:nbn:se:liu:diva-147434

N.B.: When citing this work, cite the original publication.

Stamp, K. D., Prasun, M., Lee, C. S., J aarsma, T., Piano, M. R., Albert, N. M., (2018), Nursing research in heart failure care: a position statement of the american association of heart failure nurses (AAHFN), Heart \& Lung, 47(2), 169-175. https:// doi.org/ 10.1016/j.hrtlng.2018.01.003

Original publication available at:

https:// doi.org/ 10.1016/j.hrtlng.2018.01.003

Copyright: Elsevier

http:// www.elsevier.com/

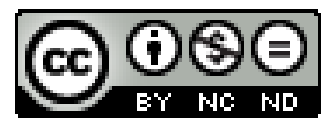




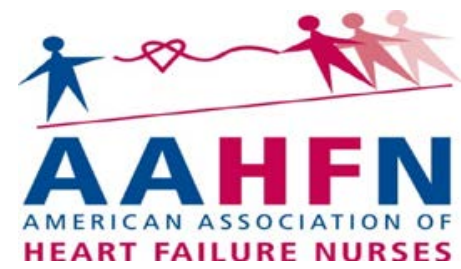

\section{Nursing Research in Heart Failure Care: A Position Statement of the American}

\section{Association of Heart Failure Nurses (AAHFN)}

Kelly D. Stamp, PhD, ANP-C, RN, CHFN-K, FAHA

Department Chair \& Associate Professor

University of North Carolina at Greensboro, School of Nursing

Marilyn Prasun, PhD, CCNS, CNL, FAHA, CHFN

Clinical Nurse Specialist, Researcher \& Coordinator of the Heart Failure Disease

Management Program

Memorial Medical Center

Christopher S. Lee, PhD, RN, FAHA, FAAN, FHFSA

Carol A Lindeman Distinguished Professor \& Associate Professor

Oregon Health \& Science University, School of Nursing

Tiny Jaarsma, PhD, FAHA

Professor

Linkoping University

Mariann R. Piano, PhD, FAAN, FAHA

Senior Associate Dean for Research

Vanderbilt University, School of Nursing

Nancy M. Albert, PhD, CCNS, CHFN, CCRN, NE-BC, FAHA, FCCM, FAAN Associate Chief Nursing Officer, Clinical Nurse Specialist

Cleveland Clinic Health System 


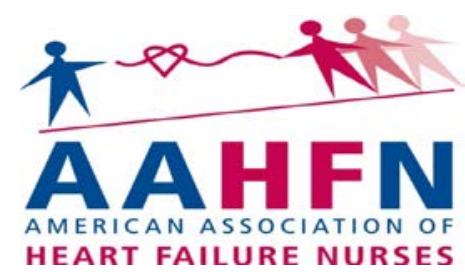

\section{Nursing Research in Heart Failure Care: A Position Statement of the American Association of Heart Failure Nurses (AAHFN)}

\section{Introduction}

Nursing research is driven by a vision toward optimizing the health and wellbeing of individuals, families and the community. When considering heart failure (HF), nurse scientists bring a unique perspective of the human condition that contributes greatly to the areas of wellness, disease prevention and management. Nurse scientists use interdisciplinary, biobehavioral and translational approaches to promote health, advance quality healthcare delivery and optimize health outcomes in HF. With aging of the population and increasing prevalence of $\mathrm{HF}$, it is more important now than at any other time in history for nursing research in HF to be robust and focused on areas of inquiry that promote the best patient outcomes. The American Association of Heart Failure Nurses (AAHFN) recognizes the need for a tailored position statement to assist researchers, funding institutions and policymakers to contribute to our knowledge base in HF, and to move HF clinical advancements and outcomes forward. The aims of this statement are to: 1 ) describe epidemiological changes in HF care over time and the societal impact of HF today; 2) describe global advancements and outcomes in HF nursing research and effects on clinical care; 3) discuss the direction of HF nursing research, the incorporation of precision care and potential new developments and gaps; and 4) put forth a call for action with recommendations for types of research designs that should be used to promote validity, sustainability and funding of future HF nursing research. 


\section{Epidemiology and Impact of Heart Failure}

The clinical syndrome of HF is a common and severe result of several cardiovascular and extra-cardiovascular diseases. HF is a progressive syndrome that typically develops over the course of many years and is associated with impaired physical functioning and quality of life as well as high symptom burden. ${ }^{1}$ The worldwide prevalence of HF is rising, ${ }^{1-3}$ and despite improvements in available therapies, HF affects millions of people and it continues to be associated with frequent healthcare utilization and premature mortality. In secular trends in HF epidemiology, patients are more likely to have multi-morbidity (i.e. co-occurrence of 2 or more chronic conditions) that includes several risk factors, such as diabetes, kidney disease, obesity, and are increasingly more likely to have a cause of death from non-cardiovascular causes. ${ }^{4}$ Incidence and prevalence

Globally and in the U.S., HF incidence rates can vary depending on the study population and diagnostic criteria used to estimate parameters. ${ }^{5}$ Over the last decade, however, similar trends were found in HF incidence and prevalence rates between the U.S. and Europe. ${ }^{6}$ For example, a large cross-sectional study of more than 2 million people living in the greater Stockholm region of Sweden in 2010 found the adjusted incidence of HF was 3.7 per 1000 person years among men and women, ${ }^{7}$ which represented about a relative $24 \%$ decrease from 2006. ${ }^{7}$ Using data from private and Medicare Advantage health plans (> 100 million persons), the incidence of HF was 2.1 per 1000 person years between 2006 and 2014. ${ }^{8}$ In the Olmsted County Minnesota cohort, age- and sex-adjusted incidence of HF was 2.19 per 1000 in 2010, ${ }^{2}$ representing a decline in the incidence of HF with reduced ejection fraction (HFrEF) (-45.1\%; 95\% CI, -33.0\% to -55.0\%) and HF with preserved ejection fraction (HFpEF) (-27.9\%; 95\% CI, $12.9 \%$ to $-40.3 \%$ ) compared with data from 2000. Slower HFpEF decline may be attributed to 
the high rates of uncontrolled hypertension, diabetes and obesity that place patients at risk for HFpEF. $^{2}$

In contrast to declining HF incidence, prevalence of HF is rising. Based on data from the U.S. National Health and Nutrition Examination Survey (NHANES) between 2009-2012, approximately 6.5 million individuals are living with HF. ${ }^{9}$ This represents an $11 \%$ increase from a similar report in 2013. ${ }^{10}$ Because the risk of HF rises with age and there is an increase in the aging population as well as patients with HF are living longer, ${ }^{1-3}$ it is anticipated that most European nations will experience a similar rise in the HF prevalence. ${ }^{6}$ In 2012 and based upon the NHANES database, HF prevalence in individuals greater than 20 years of age was 3.2\% for Black women, 2.8\% for Black men, 2.2\% for both White men and women and 2.1\% for Hispanic men and women. ${ }^{9}$ In studies that included Asian Americans, authors reported low HF incidence, HF related hospitalization and mortality rates compared to Black, White and Hispanics. ${ }^{8}$ In one national population database, NHANES, sex differences appear to be reversing and compared to men, more women ( $\geq 20$ years) are living with HF, are hospitalized for HF and have greater mortality rates. ${ }^{9}$ In other databases, higher hospitalization rates for women with HF living in the community compared to men were reported. ${ }^{8}$ Finally, changing trends in HF incidence and prevalence apply to HF patients with HFrEF and those with HFpEF, however data regarding secular trends in incidence and prevalence of HFpEF were less widespread. It is important to note that clinical characteristics are different between these groups, with HFpEF more often being older, female, having comorbidities such as hypertension, diabetes, obesity and atrial fibrillation all of the latter can impact rates of mortality and hospitalization. ${ }^{11}$ Etiology and risk factors 
Although hypertension and coronary artery disease remain leading causes of HF, diabetes mellitus and obesity are now common elements of HF etiology. ${ }^{5}$ The occurrence and contributions of different etiologies to the development of HF can vary across populations and racial/ethnic groups. Importantly though, the contemporary patient with HF will have multiple risk factors and the burden of risk factors in patients with established HF increases over time. ${ }^{5}$ In addition, the contemporary patient with HF will have multi-morbidity: the number of patients with 5 or more chronic conditions increased from $42.1 \%$ in $1988-94$ to $58.0 \%$ in $2003-2008 .{ }^{5}$

In summary, the incidence of HF is declining but prevalence is increasing because of the aging population worldwide, such that at least in the U.S. by 2030 it is predicted that there will be nearly 8 million adults with HF. ${ }^{9}$ A few important changes in the epidemiology of HF include multi-morbidity, increased hospitalization rates due to non-cardiovascular causes and increased use of long-term care facilities. Disparities continue to prevail based on race. with Black individuals experiencing an increased risk for HF, increased rate of hospitalizations and more chronic conditions such as chronic kidney disease. Although some changes in epidemiology were positive, there are still areas where further exploration is necessary.

\section{Nursing Research Contribution in Advancing HF Care}

Nurse scientists have made strong contributions to improving the care of patients with HF. Advancements most prominently have been in areas of organization of care (e.g., disease management, person-centered care), understanding mechanisms and related factors to facilitate the participation of patients in their care (self-care), and nursing interventions to improve outcomes in patients with HF.

Organization of care 
In a series of randomized trials worldwide, effectiveness of HF disease management approaches were demonstrated; such as, home-based interventions and multidisciplinary clinics. ${ }^{12}$ In a Cochrane collaboration, several models were effective: (1) case management interventions (intense monitoring of patients following discharge often involving telephone follow up and home visits); (2) clinic interventions (follow up in a HF clinic) and (3) multidisciplinary interventions (holistic approach bridging the gap between hospital admission and discharge home delivered by a team). ${ }^{13}$ Among patients with HF who were previously hospitalized, case management interventions led by HF nurses reduced readmissions and length of stay. ${ }^{14}$

A variety of HF management models have been evaluated. A single model that would universally fit all health care systems and patient populations is unrealistic. Further, in recent large scaled studies, some HF models were unsuccessful at improving outcomes; authors suggested a need for a unique approach to HF management. ${ }^{15,16}$ In a recent meta-analysis, comparative effectiveness of transitional care services after hospital discharge for HF were described. Nurse home visits and HF clinics decreased all-cause mortality. Along with nurse case management, the three program types also reduced all-cause readmissions, with no significant difference in comparative effectiveness. ${ }^{12}$ The three programs use a person-centered approach; and this approach ) was found to advance concordance between care providers and patients on treatment plans, and to improve health outcomes and patient satisfaction. ${ }^{17}$

Transitional care programs vary widely. Programs typically begin prior to hospital discharge and include the nurses' role in HF education, communication and coordination among team members, as well as implementing individualized care plans. ${ }^{18}$ In an integrative review of HF transitional care programs, improvements were found in quality of life, hospital readmission 
rates and cost of care. ${ }^{18}$ Types of interventions most successful in decreasing readmissions and maintaining or reducing cost utilized home visits in combination with telephone contact. ${ }^{18}$ Transitional programs that offered high- or moderate-intensity services reported decreased mortality, and both high- and low-intensity programs were reported to decrease HF rehospitalization. ${ }^{13}$ Many factors were associated with worsening HF symptoms leading to hospitalization that could benefit from integrated, interdisciplinary, patient-centered transition of care programs. ${ }^{19}$

Self-care in patients with HF

A large body of evidence has been published regarding self-care of patients with HF. ${ }^{20}$ In a recent meta-analysis, authors suggested that self-management interventions could have a beneficial effect on time to HF-related hospitalization, all-cause death and HF-related hospitalization. ${ }^{21}$ Self-care influences both medical and patient-centered outcomes in HF. Patients with HF who reported more effective self-care had better quality of life, lower mortality and readmission rates than those who report poor self-care. ${ }^{22-24}$ Characteristics of patients with HF who were less likely to engage in self-care behaviors included disease severity, limited knowledge, comorbidities, cognitive and emotional dysfunction and coping strategies. ${ }^{25}$ Factors that complicated self-care among patients with HF were lack and overload of caregiver support, limited social networks, living in rural areas, limited financial capacity and interaction with peers. $^{26}$

\section{Nursing Interventions to improve Outcomes}

Research has contributed to the evidence base of 'nursing interventions' to improve outcomes in patients with HF. Patient and family education has been examined and is frequently reported as an intervention in nursing research. Current HF guidelines recommend patient and 
family education and include recommended educational topics. ${ }^{3,27}$ One-hour of standardized patient education provided by a nurse educator at the time of hospital discharge increased selfcare, adherence to treatment recommendations, reduced cost of care and risk of rehospitalization. ${ }^{28}$ In addition, hospitalized patients with HF who were educated using "teachback" methods retained significantly more information and correctly answered HF specific questions. ${ }^{29}$ Further research is warranted to examine educational methods, timing, duration, effect on adherence and hospitalization, especially since in a meta-analysis of transition care programs, services that provided 'patient education alone' did not reduce all-cause rehospitalization. ${ }^{12}$

A growing body of literature exists on the effectiveness of a variety of exercise interventions for patients with HF in which nurses maintain a key role, such as a cardiac rehabilitation program for HF patients, ${ }^{30}$ home walking programs, ${ }^{31-34}$ home-based telemonitored cardiac rehabilitation, ${ }^{35,36}$ tai chi $^{37,38}$ and yoga..$^{39,40}$ Other interventions that have been tested for effects to improve patient outcomes in HF include those aimed at improving cognitive function. In preliminary studies, cognitive training led to small improvements in cognitive function, ${ }^{41,42}$ as well as positive effects on engagement in HF self-care ${ }^{43}$ and functional outcomes such as instrumental activities of daily living (e.g., medication taking, grocery shopping) that may result in reduced healthcare costs. ${ }^{44}$ In addition, family relationships among patients with HF and their caregivers were examined in several studies; investigators described both positive and neutral results of family based interventions..$^{45-49}$

This summary of HF nursing research provides a limited overview of the current body of knowledge and significant impact findings had on patients, families and providers. It also highlights gaps in the literature that may serve to guide future research (Table 1). 


\section{Precision Medicine and Heart Failure Nursing Research}

The term precision medicine is defined by the National Institutes of Nursing Research (NINR) (2015) and Institute of Medicine (IOM) (2015) as an initiative to "discover the right treatment, for the right patient, at the right time," and "discover and understand factors that either contribute to or protect one against common diseases." ${ }^{50,51}$ Another term that is commonly used is precision health, which is defined as providing the right intervention to the right person or population at the right time. ${ }^{52}$ Nurse scientists and advanced practice nurses can influence precision medicine by integrating omics into HF research to understand relevant biology, variances and environmental exposures, and by advocating that patients with HF consider enrolling in research that involves omics. It also is important for nurse scientists to consider how gaps in knowledge and solutions to common health problems can be identified through appropriated handling of big data (i.e. data characterized by high volume, velocity, variety, veracity and value). ${ }^{53}$ Although big data may entail using retrospective or prospective databases, it is important to be aware that limitations apply to research in any field.

\section{Gaps and Future Directions for HF Research}

As a means of increasing the rigor, transparency and potential translation of HF research to practice, we have identified several gaps and key future directions that should be considered in conducting HF research.

\section{Appropriate Representation}

Similar to other elements of human health, we know more about HF in older Caucasian men compared with other populations that are in many instances at greater risk for developing HF and/or suffer worse outcomes. ${ }^{54}$ Research in HF should entail balance by sex (lifetime risk of developing HF is equivalent by sex) and also entail the involvement of racial and ethnic 
minorities equal to if not greater than distributions in the greater populous. ${ }^{55}$ Research in HF should also involve other marginalized populations, including but not limited to those with language, economic and/or health literacy disadvantages. There are also several clinical phenotypes of HF based on etiology (e.g. ischemic and non-ischemic), heart function (e.g. preserved vs. reduced ejection fraction) and/or severity that should be fully considered in the sampling frame of HF research. To move HF science forward, we must view HF as being much more complex than as it manifests in older Caucasian men with ischemic disease and participants that are from the whole social spectrum instead of only highly motivated patients who are interested in making behavioral changes.

\section{Newer and Better Trial Designs}

Simple randomized control trials (RCTs) have long been viewed as the gold standard in biomedical research. Particularly in the early phase of intervention development and testing, enrichment strategies (i.e. prospective strategies to decrease heterogeneity, prognostic enrichment strategies (choosing patients with a greater likelihood of having a clinical event), and predictive enrichment strategies (choosing patients more likely to respond to the intervention) similar to those involved with drug trials should be considered. ${ }^{56}$ There are several other trial designs that have advantages over RCTs that should be considered as design

alternatives/complements in the advancement of HF research. For example, several adaptive trial designs allow for the rapid identification of therapies that have a therapeutic effect and patient populations for whom therapies are appropriate. Bayesian adaptive methods entail the modification of protocols based on information gained during the trial (e.g. outcomes and adverse events) and can include changes in intervention dosing and delivery, sample size and group allocation within a pre-specified but adaptive trial protocol. ${ }^{57,58}$ Sequential Multiple 
Assignment Randomized Trial (SMART) designs embed sequential decision rules into adaptive trial protocols based on participant response; hence, participant treatment is individualized to some degree. ${ }^{59-61}$ The continuum between explanatory trial (i.e. RCT undertaken in an ideal setting to have the best chance to demonstrate efficacy) and pragmatic trial (RCT undertaken in the "real world" and intended to help support clinical and policy decisions) should also be considered fully in the design of HF trials; ${ }^{62}$ indeed, there are nine dimensions to be considered when assessing the degree of pragmatism of a trial (i.e. eligibility, criteria, recruitment, setting, organization, flexibility in delivery, flexibility in adherence, follow-up, primary outcome, and primary analytic strategy). ${ }^{63}$ More generally, there are strategies that should be considered to strengthen trials including but not limited to block randomization with random block sizes (particularly in small trials) ${ }^{64}$ and effective implementation of run-in periods. ${ }^{65}$

\section{Larger and More Robust Non-Experimental Studies}

Data derived from small cross-sectional studies are often not generalizable and therefore do not contribute to advancement of HF science. We need larger "real world" effectiveness (observational) studies to validate prior efficacy (trial) work. Moreover, much greater attention needs to be paid toward methods used to mitigate bias in observational studies. ${ }^{66}$ One concern that is pervasive in non-experimental HF studies is the presentation of unadjusted or minimallyadjusted analysis. Unadjusted models in non-experimental research (including unadjusted ActorPartner Interdependence Models in dyadic research ${ }^{67}$ ) are the most biased and potentially misleading because they fail to take into consideration any other factor(s) that may influence relationships of interest. Simply put, unadjusted analyses should only be performed in nonexperimental studies as a means of describing the sample and presenting compulsory preliminary results. When comparisons are made between/among subgroups in non-experimental designs, 
robust methods of mitigating comparative bias should be employed. The rate of false discovery ${ }^{68}$ must be taken into account when conducting multiple analyses from the same non-experimental study. Strong consideration should be given as to the logic and consequences of merging data from multiple non-experimental studies. ${ }^{69-75}$ Merging raw data from multiple non-experimental studies should be justified scientifically and with transparency in how results might be different when considering studies to be independent. Finally, an overwhelming proportion of HF research led by nurses is not only non-experimental but also cross-sectional. Hence, it is highly recommended that non-experimental research be longitudinal to gain greater insight into how phenomena change over time and allow for participants to have more exposure to HF and its treatment.

\section{Improved characterization and description of HF subjects}

The American College of Cardiology and American Heart Association has recommended the inclusion of certain subject characteristics to facilitate cross-sectional comparison among studies and generalizability to clinical practice. ${ }^{76}$ Therefore, it is important that subject inclusion criteria detail parameters such as ejection fraction, HF duration, etiology, and common treatments. In the setting of advanced HF, other myocardial parameters such as ventricular filling pressures may be important to include. Other recommended clinical variables to include are laboratory (e.g. sodium, hemoglobin) and diagnostic test results (e.g. pulmonary function parameters). For details on Clinical Data Standards, please see:

http://circ.ahajournals.org/content/circulationaha/112/12/1888.full.pdf $){ }^{76}$ The use of tools such as the Seattle Heart Failure Model, can also add to the characterization of the HF subject cohort, in addition to providing information about prognosis. ${ }^{77}$

\section{Full Scope of Outcomes}


Although a preponderance of HF research led by nurses has focused on behavioral or patient-oriented outcomes, many others should be considered. Specifically, clinical outcomes such as survival or event risk, economic (e.g. cost-consequence and cost-effectiveness et al. following the Consolidated Health Economic Evaluation Reporting Standards statement ${ }^{77}$ ), and biological outcome (including strong and evidence-based multi-marker strategies that represent genomics and other biological technologies) should be given equal consideration as behavioral outcomes in HF research. It is also important, when appropriate to use physiologic parameters or variables to support and demonstrate a biologic link to the effects of an intervention.

\section{Harmonization of Measures}

Since the advent of the Patient-Reported Outcomes Measurement Information System (PROMIS) ${ }^{78}$ and the PROsetta stone (http://www.prosettastone.org), it is recommended that patient-reported outcome measurement be harmonized across HF studies. Instead of developing new questionnaires and measures, consideration should be given to employing existing measures with established properties and generalizability to other populations. ${ }^{79,80}$ Finally, more work needs to be done in psychometric evaluation to ensure that systematic measurement bias is not influencing how patient-reported measures are interpreted. ${ }^{81}$

\section{Examination of Heterogeneity}

Irrespective of the design of research, heterogeneity is something to be anticipated and explored. In RCTs, heterogeneity in treatment effects is common and should be explored as a means of identifying who might benefit most and least from a particular intervention. ${ }^{70}$ In nonexperimental research, the identification of previously unobserved subgroups is often an a priori strategy to identify opportunities for intervention development and/or allocation. ${ }^{82}$ Finally, heterogeneity is something that should be expected, quantified and sufficiently addressed in 
meta-analyses. ${ }^{83}$ Hence, it is recommended that heterogeneity in HF research be explored to help identify subgroups with differential response (actual or potential) to therapies.

\section{Discussion}

HF is a major global health problem. Although the incidence of HF is declining, prevalence continues to increase ${ }^{84} \mathrm{HF}$ research transcends the continuum of care from prevention, disease management to end of life, and seeks to meet the needs of a diverse population. Nurses are integral to the care of patients with HF, and their families. There is a growing body of scientific nursing knowledge that includes but is not limited to, models and organization of HF care, facilitation of patients' participation in their care (self-care) and interventions to improve patient outcomes. However, quality, rigorous research is needed to improve the lives of patients and their families while advancing nursing science. A small sampling of areas needing further exploration in HF is detailed in Table 2. Finally, translation of HF research to practice is critical to ensuring patients and their families receive holistic evidence-based care. Several gaps in the nursing literature and key future directions have been identified that should be given full consideration when engaging in HF research.

It is the position of the AAHFN and the Research Consortium that:

1. The body of nursing science in HF is developed through research and research outcomes that serve to promote the care of patients with HF, their families and the nursing profession.

2. Nurse scientists (both clinical and bench researchers) who study HF require access to the necessary resources that include, but are not limited to financial support to produce quality scientific outcomes. 
3. Research is not performed in isolation and requires collaboration with nurse scientists and other disciplines across the continuum of care, while harmonizing data measures to ensure strong, timely, quality HF studies are developed.

4. Nursing research should be led by nurses who maintain knowledge and education to develop and complete high quality, rigorous research studies, and include students and novice researchers when possible to mentor and develop future nurse scientists.

5. Nurses’ at all educational levels should remain current in advances in the science and seek to translate findings into practice.

6. Nursing research findings must be disseminated in peer-reviewed journals so that new HF knowledge can be shared and reviewed globally.

Conclusion

Despite advances in technology and medical therapy, HF continues to impact patients and families worldwide. HF nursing research is critical to managing and improving patient outcomes while promoting the nursing profession. 


\section{References}

1. Roger VL, Go AS, Lloyd-Jones DM, et al. Heart disease and stroke statistics—2012 update. Circulation 2012;125:e2-e220.

2. Gerber Y, Weston SA, Redfield MM, et al. A contemporary appraisal of the heart failure epidemic in Olmsted County, Minnesota, 2000 to 2010. JAMA Intern Med. 2015;175(6):9961004.

3. Yancy CW, Jessup M, Bozkurt B, et al. 2013 ACCF/AHA guideline for the management of heart failure. Circulation 2013; 128(16): e240-327. doi:10.1161/CIR. 0b013e31829e8776. 4. Stewart S, Riegel B, Boyd C, et al. Establishing a pragmatic framework to optimise health outcomes in heart failure and multimorbidity (ARISE-HF): A multidisciplinary position statement. Int J Cardiol 2016; 212:1-10.

5. Dunlay SM, Roger VL. Understanding the epidemic of heart failure: past, present, and future. Curr Heart Fail Rep. 2014;11:404-15.

6. Guha K, McDonagh T. Heart failure epidemiology: European perspective. Curr Cardiol Rev. 2013;9:123-7.

7. Zarrinkoub R, Wettermark B, Wändell P, et al. The epidemiology of heart failure, based on data for 2.1 million inhabitants in Sweden. Eur J Heart Fail 2013;15:995-1002.

8. Sangaralingham LR, Shah ND, Yao X, Roger VL, Dunlay SM. Incidence and early outcomes of heart failure in commercially insured and Medicare Advantage patients, 2006 to 2014. Circ Cardiovasc Qual Outcomes 2016;9:332-7.

9. Mozaffarian D, Benjamin EJ, Go AS, et al. Heart Disease and Stroke Statistics—2016 Update: A Report From the American Heart Association. Circulation 2016;133:e38-e360. 
10. Go AS, Mozaffarian D, Roger VL, et al. Executive summary: heart disease and stroke statistics--2013 update: a report from the American Heart Association. Circulation 2013;127:143-52.

11. Sherazi S, Zareba W. Diastolic heart failure: predictors of mortality. Cardiol J. 2011;18:222-32.

12. Van Spall HG, Rahman T, Mytton O, et al. Comparative effectiveness of transitional care services in patients discharged from the hospital with heart failure: a systematic review and network meta-analysis. Eur J Heart Fail 2017.

13. Takeda A, Taylor S, Taylor RS, Khan F, Krum H, Underwood M. Clinical service organisation for heart failure. Cochrane Database Syst Rev 2012;9.

14. Huntley A, Johnson R, King A, Morris R, Purdy S. Does case management for patients with heart failure based in the community reduce unplanned hospital admissions? A systematic review and meta-analysis. BMJ Open 2016;6:e010933.

15. Angermann CE, Störk S, Gelbrich G, et al. Mode of action and effects of standardized collaborative disease management on mortality and morbidity in patients with systolic heart failure: the Interdisciplinary Network for Heart Failure (INH) study. Circ Heart Fail 2012l; 5(1): 25-35 doi: 10.1161/CIRCHEARTFAILURE. 111.962969.

16. Jaarsma T, van der Wal MHL, Lesman-Leegte I, et al. Effect of moderate or intensive disease management program on outcome in patients with heart failure: Coordinating Study Evaluating Outcomes of Advising and Counseling in Heart Failure (COACH). Arch Int Med 2008;168:316-24.

17. Ekman I, Wolf A, Olsson L-E, et al. Effects of person-centred care in patients with chronic heart failure: the PCC-HF study. Eur Heart J 2012;33:1112-9. 
18. Stamp KD, Machado MA, Allen NA. Transitional care programs improve outcomes for heart failure patients: an integrative review. J Cardiovasc Nurs 2014;29:140-54.

19. Albert NM, Barnason S, Deswal A, et al. Transitions of care in heart failure. Circ Heart Fail 2015:HHF. 0000000000000006.

20. Riegel B, Moser DK, Anker SD, et al. State of the science: promoting self-care in persons with heart failure: a scientific statement from the American Heart Association. Circulation 2009;120:1141-63.

21. Jonkman NH, Westland H, Groenwold RH, et al. Do Self-Management Interventions Work in Patients With Heart Failure? Circulation 2016;133:1189-98.

22. Lee KS, Lennie TA, Dunbar SB, et al. The association between regular symptom monitoring and self-care management in patients with heart failure. J Cardiovasc Nurs 2015;30:145.

23. van der Wal MH, van Veldhuisen DJ, Veeger NJ, Rutten FH, Jaarsma T. Compliance with non-pharmacological recommendations and outcome in heart failure patients. Eur Heart J 2010;31:1486-93.

24. Vellone E, Fida R, Ghezzi V, et al. Patterns of self-care in adults with heart failure and their associations with sociodemographic and clinical characteristics, quality of life, and hospitalizations: a cluster analysis. J Cardiovasc Nurs 2017;32:180-9.

25. Siabani S, Leeder SR, Davidson PM. Barriers and facilitators to self-care in chronic heart failure: a meta-synthesis of qualitative studies. Springerplus 2013;2:1-14.

26. Strachan PH, Currie K, Harkness K, Spaling M, Clark AM. Context matters in heart failure self-care: a qualitative systematic review. J Card Fail 2014;20:448-55. 
27. McMurray JJ, Adamopoulos S, Anker SD, et al. ESC Guidelines for the diagnosis and treatment of acute and chronic heart failure 2012. Eur J Heart Fail 2012;14:803-69.

28. Koelling TM, Johnson ML, Cody RJ, Aaronson KD. Discharge education improves clinical outcomes in patients with chronic heart failure. Circulation 2005;111:179-85.

29. White M, Garbez R, Carroll M, Brinker E, Howie-Esquivel J. Is “teach-back” associated with knowledge retention and hospital readmission in hospitalized heart failure patients? J Cardiovasc Nurs 2013;28:137-46.

30. Austin J, Williams R, Ross L, Moseley L, Hutchison S. Randomised controlled trial of cardiac rehabilitation in elderly patients with heart failure. Eur J Heart Fail 2005;7:411-7. 31. Gary R. Exercise self-efficacy in older women with diastolic heart failure: results of a walking program and education intervention. J Gerontol Nurs 2006;32:31-9; quiz 40-1. 32. Gary R, Lee SYS. Physical function and quality of life in older women with diastolic heart failure: effects of a progressive walking program on sleep patterns. Prog Cardiovasc Nurs 2007;22:72-80.

33. Gary RA, Cress ME, Higgins MK, Smith AL, Dunbar SB. Combined aerobic and resistance exercise program improves task performance in patients with heart failure. Arch Phys Med Rehabil 2011;92:1371-81.

34. Gary RA, Cress ME, Higgins MK, Smith AL, Dunbar SB. A combined aerobic and resistance exercise program improves physical functional performance in patients with heart failure: a pilot study. J Cardiovasc Nurs 2012;27:418.

35. Piotrowicz E, Baranowski R, Bilinska M, et al. A new model of home-based telemonitored cardiac rehabilitation in patients with heart failure: effectiveness, quality of life, and adherence. Eur J Heart Fail 2010;12:164-71. 
36. Piotrowicz E, Jasionowska A, Banaszak-Bednarczyk M, Gwilkowska J, Piotrowicz R. ECG telemonitoring during home-based cardiac rehabilitation in heart failure patients. J Telemed Telecare 2012;18:193-7.

37. Yeh GY, Chan CW, Wayne PM, Conboy L. The Impact of Tai Chi Exercise on SelfEfficacy, Social Support, and Empowerment in Heart Failure: Insights from a Qualitative SubStudy from a Randomized Controlled Trial. PloS One 2016;11:e0154678.

38. Yeh GY, McCarthy EP, Wayne PM, et al. Tai chi exercise in patients with chronic heart failure: a randomized clinical trial. Arch Int Med 2011;171:750-7.

39. Hägglund E, Hagerman I, Dencker K, Strömberg A. Effects of yoga versus hydrotherapy training on health-related quality of life and exercise capacity in patients with heart failure: A randomized controlled study. Eur J Cardiovasc Nurs 2017:1474515117690297.

40. Khatib MN, Kirubakaran R, Gaidhane S, Shankar A, Quazi Syed Z. Yoga for improving functional capacity, quality of life and cardiovascular outcomes in people with heart failure. The Cochrane Library 2016.

41. Pressler SJ, Therrien B, Riley PL, et al. Nurse-enhanced memory intervention in heart failure: the MEMOIR study. J Card Fail 2011;17:832-43.

42. Pressler SJ, Titler M, Koelling TM, et al. Nurse-enhanced computerized cognitive training increases serum brain-derived neurotropic factor levels and improves working memory in heart failure. J Card Fail 2015;21:630-41.

43. Athilingam P, Osorio RE, Kaplan H, Oliver D, O’neachtain T, Rogal PJ. Embedding Patient Education in Mobile Platform for Patients With Heart Failure: Theory-Based Development and Beta Testing. Comput Inform Nurs 2016;34:92-8. 
44. Pressler SJ, Martineau A, Grossi J, et al. Healthcare resource use among heart failure patients in a randomized pilot study of a cognitive training intervention. Heart Lung 2013;42:332-8.

45. Dunbar SB, Clark PC, Reilly CM, et al. A trial of family partnership and education interventions in heart failure. J Card Fail 2013;19:829-41.

46. Dunbar SB, Clark PC, Stamp KD, et al. Family partnership and education interventions to reduce dietary sodium by patients with heart failure differ by family functioning. Heart Lung 2016; 45(4):311-8. doi:10.1016/j.hrtling.2016.04.001.

47. Luttik ML, Blaauwbroek A, Dijker A, Jaarsma T. Living with heart failure: partner perspectives. J Cardiovasc Nurs 2007;22:131-7.

48. Stamp KD, Dunbar SB, Clark PC, et al. Family context influences psychological outcomes of depressive symptoms and emotional quality of life in patients with heart failure. $\mathrm{J}$ Cardiovasc Nurs 2014;29:517-27.

49. Stamp KD, Dunbar SB, Clark PC, et al. Family partner intervention influences self-care confidence and treatment self-regulation in patients with heart failure. Eur J Cardiovasc Nurs 2015:1474515115572047.

50. Medicine Io. Genetics-enabled learning health care systems: gathering and using genomic information to improve patient care and research: workshop summary. Washington DC: The National Academies Press; 2015.

51. Precision medicine and NINR-supported science. 2015. at https://www.ninr.nih.gov/researchandfunding/precisionmedicine.)

52. Khoury MJ, Iademarco MF, Riley WT. Precision public health for the era of precision medicine. Am J Prev Med 2016;50:398. 
53. Westra BL, Sylvia M, Weinfurter EF, et al. Big Data science: a literature review of nursing research exemplars. Nurs Outlook 2016.

54. Writing Group M, Mozaffarian D, Benjamin EJ, et al. Heart Disease and Stroke Statistics-2016 Update: A Report From the American Heart Association. Circulation 2016;133:e38-360.

55. Heiat A, Gross CP, Krumholz HM. Representation of the elderly, women, and minorities in heart failure clinical trials. Arch Intern Med 2002;162:1682-8.

56. Department of Health and Human Services. Guidance for Industry: Enrichment Strategies for Clinical Trials to Support Approval of Human Drugs and Biological Products. In: Food \& Drug Administration, ed. http://www.fda.gov2012.

57. Collins SP, Lindsell CJ, Pang PS, et al. Bayesian adaptive trial design in acute heart failure syndromes: moving beyond the mega trial. Am Heart J 2012;164:138-45.

58. Zhou X, Liu S, Kim ES, Herbst RS, Lee JJ. Bayesian adaptive design for targeted therapy development in lung cancer--a step toward personalized medicine. Clin Trials 2008;5:181-93.

59. Collins LM, Murphy SA, Strecher V. The multiphase optimization strategy (MOST) and the sequential multiple assignment randomized trial (SMART): new methods for more potent eHealth interventions. Am J Prev Med 2007;32:S112-8.

60. Lei H, Nahum-Shani I, Lynch K, Oslin D, Murphy SA. A "SMART" design for building individualized treatment sequences. Annu Rev Clin Psychol 2012;8:21-48.

61. Thompson DR, Martin CR. Bayes' theorem and its application to cardiovascular nursing. SAGE Publications Sage UK: London, England; 2017.

62. Gartlehner G, Hansen RA, Nissman D, Lohr KN, Carey TS. Criteria for Distinguishing Effectiveness From Efficacy Trials in Systematic Reviews. Rockville (MD)2006. 
63. Loudon K, Treweek S, Sullivan F, Donnan P, Thorpe KE, Zwarenstein M. The PRECIS2 tool: designing trials that are fit for purpose. BMJ 2015;350:h2147.

64. Efird J. Blocked randomization with randomly selected block sizes. Int J Environ Res Public Health 2011;8:15-20.

65. Pablos-Mendez A, Barr RG, Shea S. Run-in periods in randomized trials: implications for the application of results in clinical practice. JAMA 1998;279:222-5.

66. von Elm E, Altman DG, Egger M, Pocock SJ, Gotzsche PC, Vandenbroucke JP. The Strengthening the Reporting of Observational Studies in Epidemiology (STROBE) statement: guidelines for reporting observational studies. J Clin Epidemiol 2007;18:800-4.

67. Kenny DA, Ledermann T. Detecting, measuring, and testing dyadic patterns in the actorpartner interdependence model. J Fam Psychol 2010;24:359-66.

68. Benjamini Y, Hochberg Y. Controlling the false discovery rate: a practical and powerful approach to multiple testing. J Royal Statist Society Series B 1995;57.

69. Gagnier JJ, Morgenstern H, Altman DG, et al. Consensus-based recommendations for investigating clinical heterogeneity in systematic reviews. BMC Med Res Methodol 2013;13:106.

70. Kent DM, Rothwell PM, Ioannidis JP, Altman DG, Hayward RA. Assessing and reporting heterogeneity in treatment effects in clinical trials: a proposal. Trials 2010;11:85. 71. Turner RM, Bird SM, Higgins JP. The Impact of Study Size on Meta-analyses: Examination of Underpowered Studies in Cochrane Reviews. PloS One 2013;8:e59202. 72. Rosén M. The aprotinin saga and the risks of conducting meta-analyses on small randomised controlled trials - a critique of a Cochrane review. BMC Health Serv Research 2009;19:34. 
73. Bowater RJ, Escarela G. Heterogeneity and study size in random-effects meta-analysis. J Applied Stat 2013;40:2-16.

74. Higgins JP, Green S. Cochrane handbook for systematic reviews of interventions: Wiley Online Library; 2008.

75. Fu R, Vandermeer BW, Shamliyan TA, et al. Handling Continuous Outcomes in Quantitative Synthesis. Rockville, MD: Agency for Healthcare Research and Quality; 2013. 76. Radford MJ, Arnold JMO, Bennett SJ, et al. ACC/AHA Key Data Elements and Definitions for Measuring the Clinical Management and Outcomes of Patients With Chronic Heart Failure. A Report of the American College of Cardiology/American Heart Association Task Force on Clinical Data Standards (Writing Committee to Develop Heart Failure Clinical Data Standards). Developed in Collaboration With the American College of Chest Physicians and the International Society for Heart and Lung Transplantation. Endorsed by the Heart Failure Society of America. Circulation 2005.

77. Husereau D, Drummond M, Petrou S, et al. Consolidated health economic evaluation reporting standards (CHEERS)—explanation and elaboration: a report of the ISPOR health economic evaluation publication guidelines good reporting practices task force. Value in Health 2013;16:231-50.

78. Cella D, Riley W, Stone A, et al. The Patient-Reported Outcomes Measurement Information System (PROMIS) developed and tested its first wave of adult self-reported health outcome item banks: 2005-2008. J Clin Epidemiol 2010;63:1179-94.

79. Choi SW, Schalet B, Cook KF, Cella D. Establishing a common metric for depressive symptoms: linking the BDI-II, CES-D, and PHQ-9 to PROMIS depression. Psychol Assess 2014;26:513-27. 
80. Cook KF, Schalet BD, Kallen MA, Rutsohn JP, Cella D. Establishing a common metric for self-reported pain: linking BPI Pain Interference and SF-36 Bodily Pain Subscale scores to the PROMIS Pain Interference metric. Qual Life Res 2015;24:2305-18.

81. Teresi JA. Overview of quantitative measurement methods. Equivalence, invariance, and differential item functioning in health applications. Med Care 2006;44:S39-49.

82. Ram N, Grimm KJ. Methods and Measures: Growth mixture modeling: A method for identifying differences in longitudinal change among unobserved groups. Int J Behav Dev 2009;33:565-76.

83. Higgins JP. Commentary: Heterogeneity in meta-analysis should be expected and appropriately quantified. Int J Epidemiol 2008;37:1158-60.

84. Dunlay SM, Roger VL. Understanding the epidemic of heart failure: past, present, and future. Curr Heart Fail Rep 2014;11:404-15. 
Table 1. Future Areas of Inquiry in Heart Failure Research

\begin{tabular}{|c|c|}
\hline Category & Topics \\
\hline Advanced Treatment & $\begin{array}{ll}\text { - } & \text { Identification and referral } \\
\text { - } & \text { Advanced treatment outcomes }\end{array}$ \\
\hline Epidemiology & $\begin{array}{ll}\text { - } & \text { Causes of death } \\
\text { - } & \text { Gender and ethnic differences } \\
\text { - } & \text { Frequency of hospitalizations and readmissions } \\
\text { - } & \text { Multi-morbidities } \\
\text { - } & \text { Chronic kidney disease and heart failure }\end{array}$ \\
\hline $\begin{array}{l}\text { Education of patients and } \\
\text { families }\end{array}$ & $\begin{array}{ll}\text { - } & \text { Educational method and/or combinations } \\
\text { - } & \text { Educational timing, duration and dosing } \\
\text { - } & \text { Depth and breadth of education on specific HF and related content } \\
\end{array}$ \\
\hline HF Management & $\begin{array}{l}\text { - } \text { Disease management programs } \\
\text { - } \text { Risk stratification } \\
\text { - } \text { Coordination and transition of care to other agencies } \\
\text { - } \text { Comorbidities } \\
\text { - } \quad \text { E health }\end{array}$ \\
\hline Self-Care & $\begin{array}{ll}\text { - } & \text { Cognition and health literary } \\
\text { - } & \text { Symptom recognition, symptom management; evaluation of } \\
\text { - } & \text { symptoms after intervening } \\
\text { - } & \text { Dietary recommendations } \\
\text { - } & \text { Exercise response (dyspnea, diaphoresis, elevated heart rate) } \\
\text { - } & \text { Stress management } \\
\text { - } & \text { Self-assessment of sleep disordered breathing to increase sleep } \\
& \text { assessment and intervention }\end{array}$ \\
\hline Family/Caregiver & $\begin{array}{ll} & \text { Family relationships and support } \\
\text { - } & \text { Caregiver burden } \\
\end{array}$ \\
\hline
\end{tabular}


Table 2. Examples of Heart Failure Nursing Research Needs

\begin{tabular}{|c|c|}
\hline $\begin{array}{l}\text { Predictors of or Interventions } \\
\text { that Improve or Enhance... }\end{array}$ & Considerations (text) and Areas of Focus (bullets) \\
\hline $\begin{array}{l}\text { Self-care maintenance behaviors } \\
\text { - } \quad \text { Smoking cessation } \\
\text { - } \quad \text { Regular physical activity; } \\
\text { - } \quad \text { Medication adherence; } \\
\text { - } \quad \text { Dietary sodium consumption }\end{array}$ & $\begin{array}{l}\text { Previous research focused on patient characteristics, heart failure } \\
\text { (HF) etiology and characteristics, comorbid conditions, health } \\
\text { literacy, and knowledge as predictors of self-care behavior } \\
\text { adherence, but there is no consensus on factors that can be used } \\
\text { as predictors } \\
\text { - Cultural, environmental, general health status and other } \\
\text { patient perspectives and factors } \\
\text { - } \quad \text { Formal clinical diagnosis and knowledge about HF } \\
\text { - Benefits of learning and coping education strategies } \\
\text { - Improving adherence }\end{array}$ \\
\hline Remote monitoring and messaging & $\begin{array}{ll}\text { - } & \text { Clinical decision system for evaluating worsening status } \\
\text { - } & \text { Clinical decision system for improving status } \\
\text { - } & \text { Biosensor systems efficacy } \\
\text { - } & \text { Expansion, adoption and effectiveness } \\
\text { - } & \text { Improving adherence to remote monitoring }\end{array}$ \\
\hline Early HF re-hospitalization & $\begin{array}{l}\text { Many predictive models are available today but most have } \\
\text { insufficient sensitivity, specificity (area under the curve) or other } \\
\text { accuracy features that limit clinical use } \\
\text { - Data-driven machine learning that provides phenome-wide } \\
\text { selection strategies and fine tuning } \\
\text { - Critical points on patient pathways including barriers to } \\
\text { evidence-based practices }\end{array}$ \\
\hline In-hospital worsening HF & $\begin{array}{l}\text { Many reports provide descriptions of rescue therapies and } \\
\text { management strategies that include medications, cardiac assist } \\
\text { devices, renal therapies and surgery; but reports are secondary } \\
\text { analyses from acute HF randomized controlled trials that may } \\
\text { not be fully generalizable to all hospitalized patients } \\
\text { - Treatment based on NYHA Class and HF Stage } \\
\text { - } \quad \text { Need best pharmacologic treatment strategies }\end{array}$ \\
\hline $\begin{array}{l}\text { Admission (versus discharge) from } \\
\text { emergency department (ED) care }\end{array}$ & $\begin{array}{l}\text { Many ED physicians admit the majority of patients treated; } \\
\text { rather than evaluating carefully for observation unit care and } \\
\text { discharge, or ED discharge with early follow-up } \\
\text { - At risk characteristics or biomarkers for poor clinical } \\
\text { outcomes and quality of life } \\
\text { - Transition from ED to home (or other disposition site) }\end{array}$ \\
\hline HF education and HF knowledge & $\begin{array}{l}\text { Research on HF patient education themes are well documented } \\
\text { but gaps in strategies that lead to effectiveness are not as } \\
\text { prevalent } \\
\text { - } \quad \text { Skills in relation to self-care self-efficacy } \\
\text { - } \quad \text { Patient and family alignment in understanding } \\
\text { - } \quad \text { Cognitive function and memory enhancement } \\
\text { - } \quad \text { Using teach back } \\
\text { - } \quad \text { Psychological and emotional factors }\end{array}$ \\
\hline Readiness for end-of-life care & $\begin{array}{ll} & \text { Multi-professional training needs } \\
\text { - } & \text { Clinical decision support }\end{array}$ \\
\hline
\end{tabular}

